\title{
'I Will Help but not Everybody' - Donating to Charity in a Deficit vs. Growth Condition: The Importance of Well-Being
}

\author{
Dorota Jasielska \\ The Maria Grzegorzewska University, \\ Warsaw, Poland
}

\author{
Monika Prusik \\ Univesity of Warsaw, Warsaw, Poland
}

\author{
Joanna Rajchert \\ The Maria Grzegorzewska University, \\ Warsaw, Poland
}

\begin{abstract}
This study examined how the reason for donating influences the likelihood of charitable giving and whether well-being and happiness shape this relation. Students $(N=85)$ were asked to donate to either children struggling with learning (to reduce a deficit) or gifted children (to support growth). We expected that although generally people are more likely to offer money to reduce a deficit than to support growth, with an increase in happiness and well-being the difference in the odds of helping, resulting from these two motivations, would be diminished. The results showed that more people opted to help struggling children than gifted ones. Well-being and happiness were not related to willingness to help. They predicted the amount of support given, although the pattern of results was different for each psychological construct. The results are discussed with reference to a revised cost-reward model of intervention and concepts of wellbeing.

Key words: deficit vs. growth, prosocial behavior, well-being, happiness, prosocial spending, donating
\end{abstract}

\section{Introduction}

Charitable giving has been increasing worldwide, with more people prepared to donate to

Acknowledgments

The Maria Grzegorzewska University has given support to the first author for this work [grant number BSTP 27/17-I]. The funding source had no involvement in the study design, in the collection, analysis and interpretation of data, in the writing of the report and in the decision to submit the article for publication.

Correspondence concerning this article should be addressed to Dr. Dorota Jasielska, Institute of Psychology, The Maria Grzegorzewska University, Szczęśliwicka 40, 02-353 Warsaw, Poland. E-mail: djasielska@aps.edu.pl

Received January 14, 2019 various causes (The Ultimate List of Charitable Giving, 2019). Nowadays, with the development of modern technologies and social media, helping has become as easy as it has ever been. One can easily donate to any cause in a few clicks. Thanks to these opportunities, it is now possible to support individuals, who did not have a chance to obtain funds easily (living in small towns or the countryside, citizens of less affluent countries). The Internet provides plenty of examples of how successful crowdfunding activities have helped individuals all over the world. One of the spectacular accomplishments in this field is the cause of Eliza O'Neill, a fouryear-old girl diagnosed with Sanfilippo syndrome, an incurable neurological disorder that destroys brain cells. Her parents have managed to raise over $\$ 2$ million via online donations to launch a clinical trial that could help save her 
life (Saving Eliza, 2019). This example shows that human generosity may help to save lives even in potentially hopeless cases. Hence, recognizing factors that determine charitable giving appears to be an important undertaking.

Charity is a type of indirect help involving giving, which can be contrasted with direct help, which involves doing something to help in person (Smithson, Amato, \& Pearce, 1983). According to Batson and Powell (2003), helping is a broad term that describes actions that can have several motivations, including egoistic benefits or external pressure. However, donating to charity is a type of helping that could also be categorized as prosocial behavior (prosocial spending) because it is a voluntary action conducted without external reinforcement, that aims to improve the situation of a person in need (Bierhoff, 2002). Some charitable donations may even be altruistic, when the ultimate goal of the donation is to improve the situation of another and the feeling of being a good person, sensitive to others' needs, is merely an unintended consequence (Batson \& Powell, 2003). From this point of view, we were interested in prosocial behavior in the form of donating to charity, which is a type of indirect helping as mentioned above.

Prosocial spending can be analyzed on various dimensions. The concepts developed by behavioral economists appear to be consistent with psychological theories of helping, as both underlie the importance of internal self-benefits of helping. For example, according to the negative state relief hypothesis (Cialdini, Darby, \& Vincent, 1973), people are more likely to help when they feel bad because prosocial behavior is a form of mood-enhancing reward. Andreoni $(1989,1990)$ proposed a model of impure altruism, in which he depicts the act of giving as a source of satisfaction described as a warm glow; hence, people make charitable donations because they gain utility from it and do not need any external rewards. Imas (2014) found that when incentives are low, individuals work harder for charity than for themselves; however, this effect disappears when the monetary rewards increase, suggesting that external incentives may diminish the warm glow effect. Studies in this area have also considered the positive influence of public visibility of an act of donating to charity (Ariely, Bracha, \& Meier, 2009) and the interplay of psychological costs and rewards on helping in critical situations (Piliavin, Dovidio, Gaertner, \& Clark, 1981).

Although they do so differently, both the abovementioned economic and psychological models refer to the costs and benefits of helping. Therefore, we based our predictions on a revised arousal: cost-reward model of intervention (Piliavin et al., 1981). According to this model, decisions about helping are determined by cost-reward calculations and the attribution of arousal, which are affected by several factors such as the situation, the person's individual traits and the characteristics of the person or group in need. As well as arousal, the costs and benefits for the helper and the target of the help are also important. Help is offered more often when the cost of not helping is high, but only when the cost of helping remains low. Engaging in charitable giving could be considered low-cost helping, when small amounts of money are involved. Research confirms that a higher cost of not helping is related to more helping when the cost of such action is low. In one study, for example, when people were convinced that the message on an unsent and lost postcard that they found was important, they were more likely to send it than when they felt the message was less important (Deaux, 1974). In another study (Bickman \& Kamzan, 1973), women in a supermarket were more likely to give money to another woman who approached them saying that she was short of money to purchase milk than frozen cookie dough. In this study, the researchers assumed that milk was a highneed item, while cookie dough was a low-need item. Helping was more common in the case of a 
high-need item. This might be interpreted as an effect of the higher cost of not helping. A similar effect of the cost of not helping, although not for the frequency of donation but for the amount of money donated, was indicated in Harris and Samerotte's (1996) study. They showed that men 'were more willing to donate money to someone who intended to use it to purchase nutritious, highly needed items [a glass of milk and a sandwich], than to one who would buy items of low nutrition, low need [a coke and a piece of cake]' (Harris \& Samerotte, 1996, p. 198). Finally, people were more in favor of donating towards tetanus vaccinations when the risk of illness was high than when the risk was low (West \& Brown, 1975).

The cost-reward model also takes into account the individual characteristics of the helper. In high-cost helping situations, supposedly only the most brave and confident people will help (Batson \& Powell, 2003). On the other hand, since charitable actions are not considered high cost but refusal to help might have more or less serious consequences, various individual characteristics should play an important role. Some scholars propose that the effect of individual characteristics manifests best when there is no situational pressure (Carlo, Eisenberg, Troyer, Switzer, \& Speer, 1991; Snyder \& Ickes, 1985), that is when the situation does not create high negative arousal that would lead to more universal behavioral reactions (withdrawing when the cost of helping is very high or helping when the cost of helping is low). Therefore, it seems important to take into consideration the emotional well-being of potential helpers before asking them for a donation. In recent years, correlates of well-being have received a lot of attention from researchers in various fields of science (such as psychology, economics, sociology and philosophy). One of the key terms in this area is happiness. It refers to the dominance of positive emotions over negative states and is often treated as a hedonic indicator of subjective well-being (Diener, Suh, Lucas, \& Smith, 1999). As a vast number of studies indicate, mood can greatly influence behavior in various social contexts (Lyubomirsky, King, \& Diener, 2005). Therefore, it seems highly relevant to scrutinize the empirical data on the links between subjective happiness and willingness to help.

A considerable number of studies confirm the existence of the glow of goodwill (Batson et al., 1979), which states that helping others is associated with positive mood. Happy people volunteer for charity more than their unhappy peers do in various types of organizations, including religious, political, educational and health-related (Thoits \& Hewitt, 2001). They also report having more interest in prosocial behavior, spending a greater percentage of their time helping others, performing more good deeds (such as stopping to help a stranger) and expressing greater intentions to perform such deeds in the future (Jasielska, 2018; Lyubomirsky et al., 2005). Moreover, Isen and Levin (1972) indicated that experimentally induced positive affect predicts doing kind things for others (for example, individuals were more likely to help to pick up papers dropped in front of them if they had 'found' a coin placed in a telephone booth by an experimenter, than if they had not). What is more, several studies show that prosocial spending, which refers to using one's own financial resources to help others, is associated with greater happiness (Aknin et al., 2013; Dunn, Aknin, \& Norton, 2014) in the majority of cultures.

Several theoretical frameworks have been proposed to explain this relationship between happiness and prosocial behavior. In a model proposed by Lyubomirsky et al. (2005), happiness (defined as a long-term propensity to experience positive emotions) is a state that frequently leads to successful (valued by society) outcomes. As these authors noted, the state of happiness signals to the person experiencing it 
that he or she is free from immediate danger and hence can seek new goals. This is consistent with the broaden-and-build theory(Fredrickson, 2001), which states that the major function of positive emotions is to produce the tendency to approach rather than to avoid and to prepare individuals to seek new experiences. As a result, positive emotions lead people to think and act in ways that promote resource building. Given the findings on the links between positive mood and helping (Batson et al., 1979; Isen \& Levin, 1972; Thoits \& Hewitt, 2001), it is possible that acting prosocially could be considered resource-building behavior. By being more helpful, people believe they are liked more (because, as the concept of image motivation states, they have a tendency to be motivated by others' perceptions - Ariely, Bracha, \& Meier, 2009) and hence may profit more from social interactions in the future (for example, through the norm of reciprocity), furnishing them with stronger and more supportive social networks. Therefore, it might be presumed that a happier person will be more likely to help a stranger because a positive mood encourages such behavior as a form of 'social investment'. In addition, it has been proposed that positive mood leads to helping by increasing positive thoughts and favorable views of other people (Baron, 1987). What is more, happy individuals might have a more favorable picture of themselves, including viewing themselves as being more generous and in control (Baumeister et al., 2003; Lyubomirsky et al., 2005), which may render readiness to help as something consistent with their self-image.

However, well-being may also interact with situational conditions influencing charitable actions. If individual characteristics manifest best in less critical situations, then we might assume that well-being would matter most in a situation of low cost of either not helping or helping. The positive effects of well-being would be more visible in a situation of low rather than high cost of not helping, because in the latter situation people would help anyway irrespective of their personal well-being.

\section{The Present Study}

The motivation behind charitable donations can have different origins. As various psychological and economic concepts indicate, it can be driven by empathic concern (Batson \& Powell, 2003), cost-reward calculations (Piliavin et al., 1981), the social context of helping (donating privately vs. publicly), the presence of material benefits, building a positive self-image or deriving satisfaction from giving (Andreoni, 1989; Ariely et al., 2009). However, to date little attention has been devoted to the purpose of giving. Our study focuses on two possible predictors of giving to charity - the goal of the charitable donation and the individual's wellbeing. We were specifically interested in whether the likelihood of donating would differ depending on whether the money was to be used to help children struggling with learning or to support those who are gifted. According to the arousal: cost-reward model, being presented with a situation in which a child is facing adversity, struggling or suffering, people readily experience discomfort and empathic arousal. Such children are not able to cope with the situation themselves, and so it represents a situation with a high cost of not helping and one that requires immediate action in order to reduce tension. Thus, helping can lead to a sense of relief as a result alleviating personal distress. This is even more plausible when helping is of low cost, as in the case of monetary donations. In contrast, presenting a story of an intelligent and capable child does not provoke discomfort because it does not involve coping with suffering. The aim is to increase the skills and fulfil the potential of a child, who is doing very well without any help. It requires a focus on strengths and future positive outcomes 
rather than on adversity. In this situation, helping is not based on the experience of negative arousal (Piliavin et al., 1981). Therefore, we expected (hypothesis 1) that people would be more likely to help struggling children than gifted ones by donating more often and more money to the former.

The second goal of our study concerned the relationship between happiness and willingness to donate to charity. As the concepts discussed above imply, if being happy is a sign that the ego is not threatened, one would be more likely to express concern for others than for the self. What is more, if positive emotions lead to resource building, people will construct positive views of others and engage in actions that promote building relationships, including prosocial behavior. However, the positive relationship between well-being and the likelihood of donating would be more visible in cases where there is no situational pressure inducing negative arousal, such as when donating to gifted children. We therefore expected (hypothesis 2) that with an increase in happiness level, differences between helping disadvantaged children and talented ones should be diminished. Based on the broaden-and-build theory (Fredrickson, 2001), we predicted that experiencing a positive mood would encourage this situation as it pro- duces a tendency to approach and enhances the availability of positive constructs about the world and others, making it easier to imagine the positive outcomes of supporting gifted children. Moreover, this situation is more likely to invoke helping behavior in the case of happier individuals as it addresses the three consequences of being happy verbalized in Fredrickson's (2001) and Lyubomirsky et al.'s (2005) conceptualizations: 1) individuals' need to focus on others rather than benefits to the self; 2) helping perceived as a long-term investment; 3) helping motivated by empathy rather than by personal distress stemming from aversive arousal. All the measures and manipulations applied in this study are presented below. The graphical design of the model is presented in Figure 1.

\section{Method}

\section{Participants}

Participants were 85 students ( 59 women) of sociology, philosophy, social work and pedagogy, aged 19-46years $(M=24.36, S D=5.10)$. The sample size was decided based on power analysis before data collection. In order to achieve a power of 0.80 (alpha level of .05, effect size of

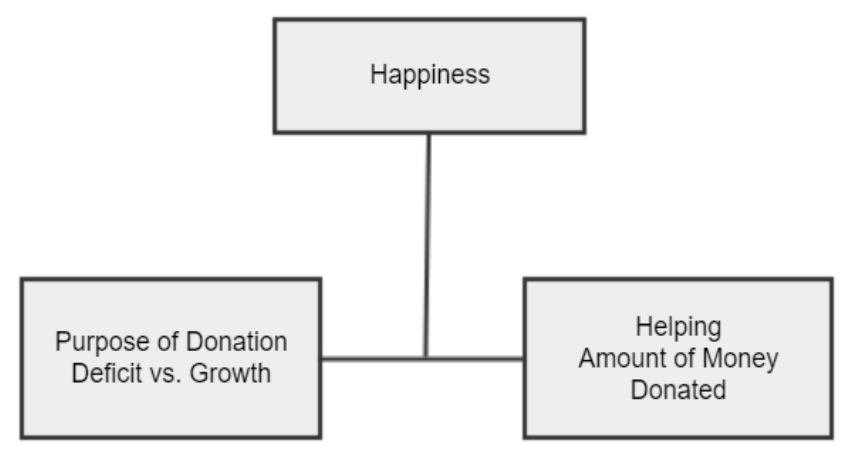

Figure 1 Graphical design of the model 
$\mathrm{f} 2=0.15$, and a medium effect size) with planned logistic regression analysis (with one or two predictors), the number of participants should be at least 25 for one predictor and 68 for two predictors analysis (based on Faul et al., 2008). The participants volunteered for the study(there were posters informing about the study in different places on the university campus) and were entered into a lottery for a bookstore gift voucher. The study was carried out in accordance with the recommendations of the Academic Ethical Review Board. All subjects gave written informed consent in accordance with the Declaration of Helsinki. None of the observations were excluded from the analyses.

\section{Measures}

Researchers on well-being recommend using multiple measures of this broad construct in order to compare results from different instruments and measure it more reliably (Biswas-Diener, Kashdan \& King, 2009). Subjective wellbeing is often analyzed with a reference to its two, interrelated dimensions - emotional (expressed in the dominance of positive emotions over negative emotions) and cognitive (described as a quality of life judged by an individual as good - Diener et al., 1999). Therefore, in the current study we decided to apply two different measures focusing on diverse aspects of well-being. In this study happiness was considered an indicator of hedonic well-being and measured with Subjective Happiness Scale (SHS, Lyubomirsky \& Lepper, 1999). This scale focuses on subjective feelings about one's own happiness and consists of four items with a 7-point response scale (such as "In general, I consider myself...”, 1 - not a very happy person to 7 - a very happy person). The scale had good reliability, $\alpha=.80$ and $\omega=.82$. Additionally, we measured eudaimonic well-being using the Psychological Wellbeing Scale (PWB, Ryff $\&$ Keyes, 1995). The scale assesses the follow- ing key aspects determining psychological quality of life: autonomy (a sense of self-determination), environmental mastery (the capacity to manage effectively one's life and surrounding world), personal growth (a sense of continued growth and development as a person), positive relations with others (the possession of quality relations with others), purpose in life (the belief that one's life is purposeful and meaningful), and self-acceptance (positive evaluations of oneself and one's past life). Participants responded to 18 statements indicating the extent to which they agreed with each of them on a 5-point scale. The measure had a satisfactory internal consistency, $\alpha=.73$ and $\omega=.73$.

\section{Procedure}

Participants were individually invited to a lab where they completed the SHS and PWB, were thanked and informed that the study was finished, and thus they left the room. At this point their willingness to help was measured. Shortly after leaving the lab a research assistant dressed as a volunteer for a fictitious foundation came to them and asked them to support a charity action by a donation in the form of money placed into a nearby box. There were two conditions related to the purpose of the donation: the money was to be collected for children with learning disabilities (deficits condition, $n=42$ ) or for gifted children to support their talents (growth condition, $n=43$ ) ${ }^{1}$. The scripts for both conditions are provided in the Appendix. After the participants made the decision whether to donate or not and how much money they were

\footnotetext{
1 This type of manipulation (fundraising for struggling vs. gifted children) was earlier used in a paperpencil study reported by Maison (2012), where participants had to evaluate the foundation and the importance of a charity action in the two conditions with different purposes of the fundraising. However, neither declaration about donating nor actual helping were assessed.
} 
willing to give, they were debriefed and informed of the purpose of the study. All the money was immediately returned to the participants. The indicators of helping were the decision whether to donate or not and the amount of donated money.

\section{Results}

The verification of the hypotheses was preceded by an investigation of the relationship between the studied constructs and fulfilment of necessary assumptions for logistic regression and regression for zero-inflated models. Our dependent variables were not normally distributed for obvious reasons: one of them "willingness to help" was coded binary, the other one "the amount of money donated" had a number of excessive zeros. Both our happiness/ well-being measurements in the form of SHS and PWB were normally distributed, which was assumed, given the graphical distribution and criteria for kurtosis and skewness (Tabachnick $\&$ Fidell, 2007). The requirements for parametric correlational analysis were met also for more advanced regression analysis. The average level of SHS was $M=4.86(S D=1.04)$ and the average level of PWB was $M=3.96(S D=0.36)$. The variables were moderately correlated, $r=$ $.52, p<.01$. This supports the idea of diverse measurement of happiness, as both measures probably grasp slightly different aspects of happiness/well-being constructs. Since gender did not differentiate the levels of SHS, $t(83)=$ $1.08, p=.285$, PWB $t(83)=-0.07, p=.948$, and was also not related to willingness to help, $\chi^{2}(1)=0.76, p=.384$, phi $=-.09, p=.384$, we decided not to include it in further analyses as a controlled variable.

\section{Logistic Regression}

The independent variable in the study was the purpose of the donation: contributing to programs for children with learning disabilities (i.e., helping children with a deficit) vs. contributing to programs for gifted children (i.e., helping unusually intelligent children fulfil their potential for intellectual growth). The dependent variables were 1) donating or not (a dichotomous variable) and 2) the amount of money donated (a continuous count variable). A logistic regression was performed to ascertain the effects of children's level of intellectual ability on the likelihood that participants would help. The logistic regression model was statistically significant, $\chi^{2}(1)=6.31, p=.012$, which suggests that the model with the purpose of donation included predicts data better than a model without independent variables (null model). The model explained 9.5\% (Nagelkerke $R^{2}$ ) of the variance in readiness to help and correctly classified $63.5 \%$ of cases. In the deficits condition, the odds of participants being willing to help were higher by a factor of 3.04 than in the growth condition. In the deficit condition, $27(64.29 \%)$ out of 42 people agreed to help, whereas in the growth condition, 16 (37.21\%) out of 43 participants in the study offered support. The purpose of donation turned out to be an important factor in willingness to help/donate. This also confirms our first hypothesis.

In order to test whether levels of happiness and psychological well-being are also related to readiness to help in the growth and deficit conditions, a series of logistic regression analyses were conducted with a purpose of donation, happiness and psychological well-being scales, and their interactions as independent variables. Both general models were at the level of statistical tendency ( $p=.063$ for SHS, $p=$ .069 for PWB). Results showed that none of the tested interactive effects were significant. Also, the donation was not related to happiness or psychological well-being. Only the purpose of donation predicted the likelihood of donations in every tested model $(p=.013-.018)$. The re- 
Table 1 Logistic regression coefficients. Willing to donate regressed on happiness and psychological wellbeing after controlling for an experimental condition.

\begin{tabular}{|c|c|c|c|c|c|c|c|c|c|}
\hline Model & $B$ & $S E$ & OR & $95 \% \mathrm{CI}$ & $\begin{array}{c}\text { Wald } \\
\text { Statistic }\end{array}$ & $p$ & $\chi^{2}$ & $d f$ & $p$ \\
\hline $\begin{array}{l}\text { Model } 1 \text { - Happiness } \\
\text { (SHS) }\end{array}$ & & & & & & & 7.29 & 3 & .063 \\
\hline SHS & 0.21 & 0.32 & 1.24 & {$[0.67,2.30]$} & 0.46 & .498 & & & \\
\hline Condition & -1.10 & 0.45 & 0.33 & {$[0.14,0.81]$} & 5.93 & .015 & & & \\
\hline SHS x Condition & 0.00 & 0.44 & 1.00 & {$[0.43,2.36]$} & 0.00 & .996 & & & \\
\hline $\begin{array}{l}\text { Model } 2 \text { - Psychological } \\
\text { well-being }(P W B)\end{array}$ & & & & & & & 7.09 & 3 & .069 \\
\hline PWB & 0.70 & 0.89 & 2.02 & {$[0.35,11.52]$} & 0.62 & .431 & & & \\
\hline Condition & -1.12 & 0.45 & 0.33 & {$[0.14,0.80]$} & 6.06 & .014 & & & \\
\hline PWB x Condition & -1.05 & 1.27 & 0.35 & {$[0.03,4.24]$} & 0.68 & .410 & & & \\
\hline
\end{tabular}

sults of a series of logistic regression analyses are reported in Table 1.

\section{Zero-Inflated Poisson Regression Models}

We also examined whether excess zero ( 0 donation) in the growth and deficit conditions was related to the constructs of well-being (SHS \& PWB) and their subscales, as well as whether the amount of money differed between the two conditions. Our suspicion, based on the graphical inspection, that the amount of money donated had a form of either Poisson or negative binomial distribution, was supported by the results of the Anderson Darling test. It was confirmed that our dependent variable had a Poisson distribution (Statistics $=190.21, p>.05)$, but did not have a negative binomial distribution $(p<.05)$. The excess zeros constituted $49.4 \%$ of the distribution. As for the count model (including data from participants who offered money) the average donation was $M=476.05$ $(S D=375.96)$ with minimum donation of 80 to maximum donation of 2000 pennies.

That is why we decided to test our hypotheses by employing Zero-Inflated Poisson re- gression (ZIP) models. ZIP methodology is widely discussed in various sources (e.g., He, Tang, Wang, \& Crits-Christoph, 2014). The outcomes of the series of ZIP analyses including the interaction terms are presented in Table 2.

According to the results, the purpose of donation was related both to excess zero ( 0 donation) as well as to the amount of donation. The variable purpose of donation increased the probability of being in the zero-donation group but it was also related to the amount of the donation. The probability for being in the zerodonation group was significantly higher for the "growth" condition. The amount of donation was significantly higher in the "deficit" condition for every model tested. This again confirms our first hypothesis. However, excess zeros were not related to SHS, PWB, and their subscales. On the contrary, happiness and psychological well-being were related to the amount of donation. Higher levels of SHS, but lower levels of PWB, were related to higher donation. Also, interactions for the count model were statistically significant and they are presented in Figures 2-3. 
Table 2 Zero-Inflated Poisson regression coefficients with interaction terms. The frequency of donation regressed on happiness (SHS) and psychological well-being (PWB) after controlling for an experimental condition

\begin{tabular}{|c|c|c|c|c|c|c|c|c|c|c|}
\hline \multirow[b]{2}{*}{ Model } & \multicolumn{4}{|c|}{$\begin{array}{l}\text { Count Model } \\
\text { Coefficients }\end{array}$} & \multicolumn{4}{|c|}{$\begin{array}{c}\text { Zero-Inflation } \\
\text { Model Coefficients }\end{array}$} & \multirow[t]{2}{*}{ AIC } & \multirow{2}{*}{$\begin{array}{c}\text { Log- } \\
\text { likelihood }\end{array}$} \\
\hline & Estimate & $S E$ & $z$ & $p$ & Estimate & $S E$ & $z$ & $p$ & & \\
\hline \multicolumn{11}{|l|}{ Model 1 - } \\
\hline \multicolumn{11}{|l|}{ SHS } \\
\hline Block 1 & & & & & & & & & 11050.45 & -5519.23 \\
\hline SHS & $0.02 *$ & 0.01 & 2.17 & .030 & -0.22 & 0.22 & -0.98 & .325 & & \\
\hline Condition & $-0.05^{* *}$ & 0.02 & -3.11 & .002 & $1.10^{*}$ & 0.45 & 2.44 & .015 & & \\
\hline Block 2 & & & & & & & & & 10984.51 & $-5484.26^{\mathrm{a}}$ \\
\hline SHS & $0.06^{* * *}$ & 0.01 & 6.61 & $<.001$ & -0.21 & 0.32 & -0.68 & .497 & & \\
\hline Condition & $0.58 * * *$ & 0.08 & 7.63 & $<.001$ & 1.12 & 2.18 & 0.51 & .608 & & \\
\hline SHS x & & & & $<.001$ & & & & & & \\
\hline Condition & $-0.13 * * *$ & 0.02 & -8.34 & & 0.00 & 0.44 & -0.01 & .996 & & \\
\hline \multirow{2}{*}{\multicolumn{11}{|c|}{$\begin{array}{l}\text { Model 2 - } \\
\text { PWB }\end{array}$}} \\
\hline & & & & & & & & & & \\
\hline Block 1 & & & & & & & & & 10593.26 & -5290.63 \\
\hline PWB & $-0.40 * * *$ & 0.02 & -21.75 & $<.001$ & -0.19 & 0.63 & -0.30 & .765 & & \\
\hline Condition & $-0.08 * * *$ & 0.02 & -5.40 & $<.001$ & $1.11^{*}$ & 0.45 & 2.45 & .014 & & \\
\hline Block 2 & & & & & & & & & 10187.18 & $-5085.59^{\mathrm{a}}$ \\
\hline PWB & $-0.64 * * *$ & 0.02 & -30.01 & $<.001$ & -0.70 & 0.89 & -0.79 & .431 & & \\
\hline Condition & $-3.13^{* * *}$ & 0.15 & -20.73 & $<.001$ & -3.04 & 5.03 & -0.60 & .546 & & \\
\hline PWB x & & & & $<.001$ & & & & & & \\
\hline Condition & $0.78^{* * *}$ & 0.04 & 20.39 & & 1.05 & 1.27 & 0.83 & .410 & & \\
\hline
\end{tabular}

Note. $^{\text {a }}$ - based on LTR there was a significant improvement in a model by addition of interaction term (compared to the 0.05 critical-value from the Chi-square distribution with $2 d f$, which is 5.99).

${ }^{*} p<.05,{ }^{* *} p<.01,{ }^{* * *} p<.001$

SHS

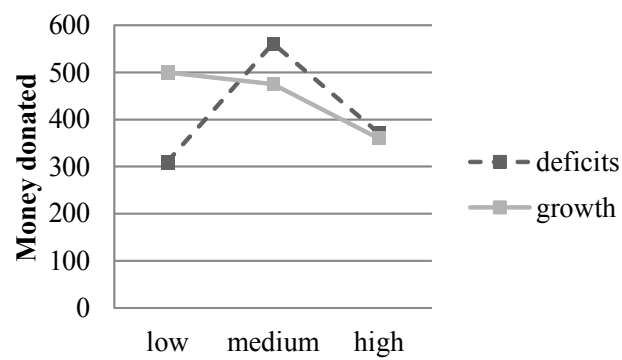

Figure 2 Interaction effect of SHS and experimental condition on money donation.
PWB

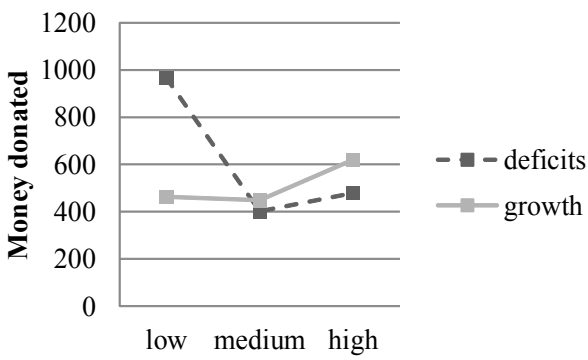

Figure 3 Interaction effect of PWB and experimental condition on money donation. 
A closer examination of the interaction effect for SHS and Condition showed that at low levels of SHS higher donations were made in the "growth" condition (Estimate $=0.48, S E=0.06$, $p<.001$ ), but at medium levels of SHS that higher donations were typical in the "deficits" condition $($ Estimate $=-0.17, S E=0.16, p<.001)$. There was no such difference for high levels of SHS regarding the type of condition (Estimate = $-0.03, S E=0.42, p=.458$ ). Overall, higher SHS was related to higher donations in the "deficits" condition (Estimate $=0.06, S E=0.01, p<$ $.001)$ and lower donations in the "growth" condition (Estimate $=-0.07, S E=0.01, p<.001)$.

In relation to psychological well-being, at low levels of PWB, donations were higher in the "deficits" condition (Estimate $=-0.74, S E=0.03$, $p<.001)$, while at medium (Estimate $=0.11, S E=$ $0.02, p<.001)$ and high levels (Estimate $=0.26$, $S E=0.04, p<.001)$ of PWB donations were higher in the "growth" condition. In general, the increase in PWB was related to smaller donations in the "deficits" condition (Estimate = $-0.64, S E=0.02, p<.001$ ), and higher donations in the "growth" condition (Estimate $=0.14$, $S E=0.03, p<.001)$.

\section{Discussion}

The aim of our study was to investigate whether focus on deficits vs. growth and the level of happiness predict prosocial behavior. We hypothesized that the purpose of the charity action would affect the willingness to help, with a generally bigger propensity to support children who struggle with learning rather than those who are particularly gifted and need support in the development of their talents. We also expected that this difference would be diminished with an increase in happiness level, since happiness promotes prosocial behavior.

Results confirmed that the purpose of the donation was an important factor influencing not only whether a person would help or not but also the amount of help. Participants were more likely to offer money for struggling children than for gifted ones. Moreover, in general they were willing to give more money to children in "deficit" condition than to children in "growth" condition. This result supports our first hypothesis and the revised cost-reward model of intervention (Piliavin et al., 1981), suggesting that helping may be a result of a willingness to diminish negative arousal elicited by a confrontation with suffering. Participants might have experienced discomfort while hearing about children who struggle with learning, but that discomfort could easily be reduced by donating. In this situation, helping offered a reward (a relief from distress) at a relatively small cost. On the other hand, the growth condition did not elicit an unpleasant state, so there was no reward coming from experiencing relief. These differences can also be explained with reference to theories about different evaluative standards for processing information related to deprivation of needs and development of values (Jarymowicz \& Imbir, 2014) and to the concept of negative bias (Ito, Larsen, Smith, \& Cacioppo, 1998), which imply that information about deficits is processed differently from information about growth, with the former evoking an automatic emotional response and the latter requiring deliberation and cognitive activity in order to predict the future positive outcomes of helping (such as enhancing the success of a gifted individual).

Our second hypothesis stated that, with a higher happiness level, differences in helping in the deficit and growth conditions would be diminished. Our prediction did not receive empirical support regarding the frequency of helping, as there was no relationship between happiness and the frequency of acts of prosocial behavior, irrespective of the condition of the study. There are several possible explanations for this result. Firstly, prosocial behavior may be more likely to happen in a situation in which 
positive emotions are elicited, because the person experiences arousal that facilitates positive thoughts about others (Baron, 1987). This produces a tendency to approach, which leads to acting in ways that promote resource building (i.e., helping others). In fact, the design of the previous studies involved experiencing a positive affect first and then giving participants the opportunity to help (Isen \& Levin, 1972). In our study, we wanted to check whether similar effects would be obtained for the general level of well-being, not only for the experimentally induced state. Since the measures of happiness and PWB refer to the global positive evaluation of the subject's life (or several aspects of it), which is based on the frequency rather than on the intensity of experienced emotions (Diener, Sandvik, \& Pavot, 2009), it is possible that due to the lack of strong affect, the benefits of a positive state described by the broaden-andbuild theory (Fredrickson, 2001) were less prominent in the current study. Moreover, there is evidence that the effect of 'feel good, do good' holds only when the requested help is not costly to the helper (Bartlett \& DeSteno, 2006). Donating money from personal resources could have been perceived by participants as a relatively big cost. Therefore, to address this issue in future studies, it would be beneficial to compare the relationship of happiness with different types of helping (including donating).

However, it is important to note that in the group of participants who helped, both happiness and psychological well-being were related to the amount of donations, yet, for each construct, different patterns of results were obtained. Higher levels of subjective happiness were associated with higher amounts of money given in the deficit condition, but lower amounts in the growth condition. In the case of psychological well-being, the effect was reversed: higher levels of PWB were related to higher donations in the growth condition but lower donations in the deficit condition. Those re- sults are contradictory to our assumptions. Therefore, the interpretation of the results can be only speculative in nature, because, without measuring motivation and arousal, we are not able to verify the mechanism underlying the obtained effects. There are several ways of explaining these results, which we present below.

For participants with high levels of subjective happiness, no difference was observed regarding the type of manipulation; amounts of money given were similar in both conditions. This effect supports our expectations based on the theory of Lyubomirsky et al. (2005) about the benefits of happiness, which claims that at high levels of this state the differences between donating money in deficit and growth conditions would be diminished. Higher levels of subjective happiness were also related to a greater amount of money donated in the deficit condition. This result is consistent with findings from studies on prosocial spending that indicate a positive relationship between happiness and donating money (Aknin et al., 2013; Dunn, Aknin, \& Norton, 2014). The question remains why a positive relationship between happiness and the amount of money donated was observed only in the deficit condition, and why higher donations were made at low levels of happiness in the growth condition. Perhaps these differences can be explained by the revised cost-reward model of intervention (Piliavin et al., 1981), in which a decision about helping is a result of cost-reward calculations that are affected by several situational and personal factors, which might involve a complex interplay between happiness and the type of donation. However, since in the present study we did not investigate the participants' motivation, such supposition remains a speculation, and further research is required in order to verify it.

Unlike the level of subjective happiness, lower levels of psychological well-being were related to bigger donations. Yet again, different pat- 
terns were obtained for the deficits condition (negative relation between well-being and amount of donation) and the growth condition (positive relation between well-being and amount of money donated). Apparently, those two scales, both aimed at measuring well-being but only moderately correlated, capture a slightly different phenomenon. Whereas SHS provides a global, subjective assessment of whether one is a happy or an unhappy person (Lyubomirsky \& Lepper, 1999), PWB measures well-being as a multidimensional construct consisting of autonomy, environmental mastery, personal growth, positive relations with others, purpose in life, and self-acceptance. Most importantly, none of the components of PWB refer to positive affect. They encompass positive qualities or attributes of a person rather than pleasant experiences, which qualifies this scale as an indicator of eudaimonic well-being, focused on the realization of human potential, based on personal dispositions and talents (Ryff, 2017). Personal development, achieving important goals and life purposes, are central criteria for psychological well-being. People high on PWB are described as having big potential, talents, and other positive propensities (Ryff, 2017). Hence, it is possible that they were willing to offer more money in this condition because they saw the benefits from such investment. Moreover, research shows that giving help to others who are similar is more probable (Batson et al., 1997; Dovidio et al., 1997; Karylowski, 1976; Sole, Marton, \& Horstein, 1975). This can explain why, in the growth condition, the more the participants experienced psychological well-being the more money they offered for gifted children; they most likely identified with the value of personal development. On the contrary, in the deficit condition, with the increase of the PWB, the amounts of money given declined. Perhaps for the participants high on psychological well-being, it was harder to identify with the needs of struggling children (contrary to participants low on PWB), and hence they offered less money. In the future, it would be advisable to verify this supposition by asking participants about their motivation for donating.

There are a number of limitations in the current study that warrant mention. First of all, we did not control for the level of positive affect. It is possible that some participants had unpleasant experiences just before entering the laboratory and despite a global positive evaluation of life, their current affective state was negative and that had an impact on helping. Hence, it would be useful to add an assessment of positive and negative affect (and its intensity) just before asking for a donation. Future studies would also benefit from controlling the level of empathic concern. That would allow for checking as to how this variable affects the relationship between happiness and prosocial behavior. Finally, it would be beneficial to check for the participant's motivation regarding the donation (or choosing not to donate). Since participants' interpretations of the given situation, their values, or previous experiences might have affected helping, having an insight into such data could have shed some light on the apparently complex relationship between happiness and donating. Nevertheless, it is important to note that our study was partially a field experiment. This approach is considered important in the arena of social psychology, as it examines a real behavior (Grzyb, 2016). Since field experiments aim to reflect the natural settings, it is difficult to measure all intermediate variables. Moreover, examining the same effect in a more controlled settings may result in obtaining completely different results, because participants might want to leave a good impression (Grzyb, 2016, 2017). The question remains: which data would be better predictors of the actual behavior of participants?

Despite these limitations, the results reported in this paper lead to interesting conclusions 
regarding the determinants of prosocial behavior. First, as predicted, it was easier to encourage somebody to offer money to charity when the purpose of the action was dealing with deficits rather than promoting growth. Contrary to our expectations, well-being was not related to the willingness to help either in the deficit or in the growth condition. This result might be due to the design of the study (measuring happiness and PWB, not positive affect) or the beneficiaries of the help (strangers, with whom there was no direct interaction). Yet, both subjective happiness and psychological well-being were related to the amount of money donated, with higher levels of subjective happiness but lower levels of psychological well-being related to higher donations. This effect, confirmed for the two separate measures of happiness, implies that the act of helping and the amount of money donated are two diverse behaviors that capture different aspects of helping. A better understanding of the differences between them and factors underlying various aspects of prosocial spending is needed and should be a goal for future studies.

\section{References}

Aknin, L. B., Barrington-Leigh, C. P., Dunn, E. W., Helliwell, J. F., Burns, J., Biswas-Diener, R., Kemeza, I. Nyende, P., Ashton-James, C. E., \& Norton, M. I. (2013). Prosocial spending and well-being: Crosscultural evidence for a psychological universal. Journal of Personality and Social Psychology, 104(4), 635-652.

Andreoni, J. (1989). Giving with impure altruism: Applications to charity and Ricardian equivalence. Journal of Political Economy, 97(6), 14471458 .

Andreoni, J. (1990). Impure altruism and donations to public goods: A theory of warm-glow giving. The Economic Journal, 100(401), 464-477.

Ariely, D., Bracha, A., \& Meier, S. (2009). Doing good or doing well? Image motivation and monetary incentives in behaving prosocially. American Economic Review, 99(1), 544-555.

Baron, R. A. (1987). Interviewer's moods and reactions to job applicants: The influence of affective states on applied social judgments. Journal of Applied Social Psychology, 17, 911-926.

Bartlett, M. Y., \& DeSteno, D. (2006). Gratitude and prosocial behavior: Helping when it costs you. Psychological Science, 17(4), 319-325.

Batson, C. D., Coke, J. S., Chard, F., Smith, D., \& Taliaferro, A. (1979). Generality of the "glow of goodwill": Effects of mood on helping and information acquisition. Social Psychology Quarterly, 42(2), 176-179.

Batson, C. D., Sager, K., Garst, E., Kang, M., Rubchinsky, K., \& Dawson, K. (1997). Is empathyinduced helping due to self-other merging? Journal of Personality and Social Psychology, 73(3), 495509.

Batson, C. D., \& Powell, A. A. (2003). Altruism and prosocial behaviour. In T. Millon, M. J. Lerner, \& I. B. Weiner (Eds.). Handbook of psychology, Volume 5: Personality and social psychology (pp. 463-485). John Wiley \& Sons, Inc.

Baumeister, R. F., Campbell, J. D., Krueger, J. I., \& Vohs, K. D. (2003). Does high self-esteem cause better performance, interpersonal success, happiness, or healthier lifestyles? Psychological Science in the Public Interest, 4(1), 1-44.

Bickman, L., \& Kamzan, M. (1973). The effect of race and need on helping behavior. Journal of Social Psychology, 89, 73-77.

Bierhoff, H. W. (2002). Just world, social responsibility, and helping behavior. In M. Ross \& D. T. Miller (Eds.), The justice motive in everyday life (pp. 189203). Cambridge: Cambridge University Press.

Biswas-Diener, R., Kashdan, T. B., \& King, L. A. (2009). Two traditions of happiness research, not two distinct types of happiness. The Journal of Positive Psychology, 4(3), 208-211.

Carlo, G., Eisenberg, N., Troyer, D., Switzer, G., \& Speer, A. L. (1991). The altruistic personality: In what contexts is it apparent?. Journal of Personality and Social Psychology, 61(3), 450-458.

Cialdini, R. B., Darby, B. L., \& Vincent, J. E. (1973). Transgression and altruism: A case for hedonism. Journal of Experimental Social Psychology, 9(6), 502-516.

Deaux, K. (1974). Anonymous altruism: Extending the lost letter technique. Journal of Social Psychology, 92, 61-66.

Diener, E., Suh, E. M., Lucas, R. E., \& Smith, H. E. (1999). Subjective well-being: Three decades of progress. Psychological Bulletin, 125, 276-302.

Diener, E., Sandvik, E., \& Pavot, W. (2009). Happiness is the frequency, not the intensity, of positive versus negative affect. In E. Diener (Ed.), Social indicators research series: Vol. 39. Assessing wellbeing: The collected works of Ed Diener (pp. 213- 
231). New York, NY, US: Springer Science + Business Media.

Dovidio, J. F., Gaertner, S. L., Validzic, A., Matoka, K., Johnson, B., \& Frazier, S. (1997). Extending the benefits of recategorization: Evaluations, self-disclosure, and helping. Journal of Experimental Social Psychology, 33(4), 401-420.

Dunn, E. W., Aknin, L. B., \& Norton, M. I. (2014). Prosocial spending and happiness using money to benefit others pays off. Current Directions in Psychological Science, 23(1), 41-47.

Faul, F., Erdfelder, E., Buchner, A., \& Lang, A. G. (2008). $G$ PPower Version 3.1.2 [computer software]. Uiversität Kiel, Germany. Retrieved from: http:// www.psycho.uni-duesseldorf.de/abteilungen/a ap/ gpower3/who-we-are

Fredrickson, B. L. (2001). The role of positive emotions in positive psychology: The broaden-and-build theory of positive emotions. American Psychologist, 56(3), 218-226.

Grzyb, T. (2016). Why can't we just ask? The influence of research methods on results. The case of the "bystander effect". Polish Psychological Bulletin, 47(2), 233-235.

Grzyb, T. (2017). Obtaining informed consent from study participants and results of field studies. Methodological problems caused by the literal treatment of codes of ethics. Polish Psychological Bulletin, 48(2), 288-292.

He, H., Tang, W., Wang, W., \& Crits-Christoph, P. (2014). Structural zeroes and zero-inflated models. Shanghai Archives of Psychiatry, 26(4), 236-242.

Harris, M. B., \& Samerotte, G. C. (1976). The effects of actual and attempted theft, need and a previous favor on altruism. Journal of Social Psychology, 99, 193-202.

Imas, A. (2014). Working for the "warm glow": On the benefits and limits of prosocial incentives. Journal of Public Economics, 114, 14-18.

Isen, A. M., \& Levin, P. F. (1972). Effect of feeling good on helping: Cookies and kindness. Journal of Personality and Social Psychology, 21(3), 384-388.

Ito, T. A., Larsen, J. T., Smith, N. K., \& Cacioppo, J. T. (1998). Negative information weighs more heavily on the brain: The negativity bias in evaluative categorizations. Journal of Personality and Social Psychology, 75(4), 887-900.

Jarymowicz, M. T., \& Imbir, K. K. (2015). Toward a human emotions taxonomy (based on their automatic vs. reflective origin). Emotion Review, 7(2), 183-188.

Jasielska, D. (2018). The moderating role of kindness on the relation between trust and happiness. Current Psychology, 1-9.
Karylowski, J. (1976). Self-esteem, similarity, liking and helping. Personality and Social Psychology Bulletin, 2(1), 71-74.

Lyubomirsky, S., King, L., \& Diener, E. (2005). The benefits of frequent positive affect: Does happiness lead to success? Psychological Bulletin, 131(6), 803855 .

Lyubomirsky, S., \& Lepper, H. S. (1999). A measure of subjective happiness: Preliminary reliability and construct validation. Social Indicators Research, 46(2), 137-155.

Maison, D. (2012). Chętnie pomogę, ale zależy komu. O złożonych uwarunkowaniach podejmowania działań prospołecznych. In A. Szuster, D. Maison, \& D. Karwowska (Eds). W stronę podmiotowości: $O$ emocjonalności, tożsamości, dobrych uczynkach $i$ pożytkach płynacych z porannego wstawania. Sopot: Smak Słowa.

Piliavin, J. A. , Dovidio, J. F., Gaertner, S. L., \& Clark, R. D. (1981). Emergency intervention. New York: Academic Press.

Ryff, C. D., \& Keyes, C. L. M. (1995). The structure of psychological well-being revisited. Journal of Personality and Social Psychology, 69(4), 719727.

Ryff, C. D. (2017). Eudaimonic well-being, inequality, and health: Recent findings and future directions. International Review of Economics, 64(2), 159-178.

Saving Eliza (2019, July 15 $\left.5^{\text {th }}\right)$. Retrieved from: https:/ /www.gofundme.com/ElizaONeill

Smithson, M., Amato, P. R., \& Pearce, P. L. (1983). Dimensions of helping behaviour. Pergamon Press. Snyder, M., \& Ickes, W. (1985). Personality and social behavior. Handbook of Social Psychology, 2(3), 883947.

Sole, K., Marton, J., \& Hornstein, H. A. (1975). Opinion similarity and helping: Three field experiments investigating the bases of promotive tension. Journal of Experimental Social Psychology, 11(1), 113.

Tabachnick, B. G., \& Fidell, F. S. (2007). Using multivariate statistics. Pearson, Boston.

The Ultimate List Of Charitable Giving Statistics For 2018 (2019, May 12 $\left.2^{\text {th }}\right)$. Retrieved from: https:// nonprofitssource.com/online-giving-statistics/

Thoits, P. A., \& Hewitt, L. N. (2001). Volunteer work and well-being. Journal of Health and Social Behaviour, 42(2), 115-131.

West, S. G., \& Brown, T. J. (1975). Physical attractiveness, the severity of the emergency and helping: A field experiment and interpersonal simulation. Journal of Experimental Social Psychology, 11, 531538 . 


\section{Appendix}

Scripts used in the study

Script used in the deficit condition:

According to Centre for Public Opinion Research every fifth child in Polish schools struggles with learning. This month our foundation runs an action "Students and scientists for helping children" at Warsaw universities. The action is intended to help primary school children who have learning difficulties. The foundation wants to provide these children with the possibility of additional tutoring, which will allow them to level up their educational opportunities.

As a part of the campaign, there will be fundraising at Warsaw universities for schools that cannot afford remuneration for teachers for conducting additional classes.

Please help the children with learning difficulties!

\section{Script used in the growth condition:}

According to Centre for Public Opinion Research every fifth child in Polish schools is exceptionally gifted. This month our foundation runs an action "Students and scientists for helping children" at Warsaw universities. The action is intended to help primary school children who have outstanding learning achievements. The foundation wants to provide these children with the possibility of additional tutoring, which will allow them to develop their talents.

As a part of the campaign, there will be fundraising at Warsaw universities for schools that cannot afford remuneration for teachers for conducting additional classes.

Please help exceptionally gifted children to develop their talents! 